\title{
Os impactos das novas tecnologias de informação e comunicação no direito e no processo do trabalho
}

\section{The impacts of new technologies of informations and communication in law and in labour procedure}

\author{
Victor Hugo Almeida*
}

Resumo

Impulsionada pelo recente processo de globalização da economia, a Revolução das Tecnologias de Informação e Comunicação provocou algumas descobertas tecnológicas no início do Século XX, responsáveis pela reestruturação produtiva, pela instituição de novas formas de trabalho e pela extinção de outras até então existentes. Todavia, se por um lado a Revolução Tecnológica possibilitou modificar o conteúdo organizacional do trabalho, criando novas demandas, regras de produção, de sociabilidade e de sobrevivência, por outro, criou novas formas de agir, de pensar, de interagir e de viver, impactando no Direito e no Processo do Trabalho. Nesse sentido, tendo em vista a jurisprudência trabalhista brasileira, o objetivo deste artigo é examinar os impactos no Direito e no Processo do Trabalho do uso de dados obtidos em redes sociais e em aplicativos de comunicação. Trata-se de uma abordagem construída a partir do método de levantamento por meio da técnica de pesquisa bibliográfica, cujos dados foram analisados através do método dedutivo. Como conclusão, evidencia-se que as grandes transformações não decorreram apenas da sofisticação dos aparatos tecnológicos, mas, principalmente, do modo como eles são utilizados. O uso dessas modernas tecnologias no contexto laboral desencadeia diversas consequências para todos aqueles que nele se encontram. Por isso, é preciso fixar regras para a utilização desses recursos

* Doutorado em Direito do Trabalho pela Faculdade de Direito da Universidade de São Paulo (USP) - Largo São Francisco. Professor de Direito do Trabalho da Universidade Estadual Paulista Júlio de Mesquita Filho- UNESP / Campus Franca (SP). Docente vinculado ao Programa de Pós-Graduação em Direito (Mestrado) da Universidade Estadual Paulista Júlio de Mesquita Filho - UNESP / Campus Franca (SP). São Paulo - São Paulo - Brasil. E-mail: victorhugo.professor@ gmail.com 
tecnológicos, antevendo os desdobramentos decorrentes, os quais, tantas vezes, vão muito além da real finalidade para a qual foram criados.

Palavras-chave: Direito e Processo do Trabalho. Tecnologias da informação e comunicação. Facebook. WhatsApp.

\section{Abstract}

Driven by the recent globalization of the economy, the Revolution of Information and Communication Technologies brought some technological breakthroughs in the early twentieth century, responsible for production restructuring, the introduction of new ways of working and the extinction of others and the extinction of other hitherto existing. However, if on one hand the technological revolution changed the organizational content of the work, creating new demands, production rules, sociability and survival, on the other, created new ways of acting, thinking, interacting and living, impacting on Law and Labour Procedure. In this regard, with a view to brazilian labour jurisprudence, the purpose of this article is to examine the impacts on Law and Procedure of data obtained on social networks and communication applications. It is an approach constructed from the survey method through the technical of bibliographical research, whose data were analysed through dedutive method. In conclusion, the major changes in the labour context did not necessarily originate from the the sophistication of technological means, but, mainly, of the way they are used. Therefore, it is necessary to establish rules for the use of these technological resources, foreseeing the consequences arising from it, which so often go far beyond the real purpose for which they were created.

Keywords: Law and Labour Procedure. Information and communication technology. Facebook. WhatsApp.

\section{Introdução}

A necessidade de se reinventar e de readaptar o seu entorno a partir da ressignificação da sua própria visão de mundo - nem sempre espontânea - conduziu o ser humano a diversos desafios e conquistas ao longo da história da humanidade. Basta recordar-se de que as mudanças técnicas, econômicas e sociais ocorridas na Inglaterra, no final do século XVIII, nasceram da necessidade humana e, ao mesmo 
passo, criaram outras demandas, reverberando por toda a Europa e, posteriormente, por todos os outros continentes.

Impulsionada pelo recente processo de globalização da economia, a Revolução das Tecnologias de Informação e Comunicação ${ }^{1}$ provocou algumas descobertas tecnológicas no início do século $\mathrm{XX}$, responsáveis pela reestruturação produtiva, pela instituição de novas formas de trabalho e pela extinção de outras até então existentes.

Iniciado nos Estados Unidos da década de 1970 (CASTELLS, 1999), esse paradigma tecnológico tornou-se mais expressivo no Brasil após a privatização das empresas públicas e do desmonte do setor produtivo estatal no final da década de 1990. Nesse período, diversas empresas públicas de telecomunicações foram privatizadas e incorporadas por multinacionais estrangeiras, favorecendo o ingresso de novas tecnologias no país responsáveis pela modernização do sistema de informação e comunicação brasileiro - telefonia móvel, internet, serviços de transmissão de dados etc. (ALMEIDA, 2013). Dentre essas descobertas tecnológicas, aponta Otavio Pinto e Silva (2004) para a crescente automação, os novos tipos de materiais usados em todos os setores da produção e as imensas facilidades obtidas no campo das comunicações.

Para Jacob Gorender (1997), a recente Revolução Tecnológica, sobretudo na telemática, decorreu das transformações no sistema capitalista mundial, cujos efeitos são percebidos na organização do trabalho, nos métodos de produção, nas relações laborais e na política financeira dos governos. Frente a esse cenário, é inegável que a contemporânea Revolução das Tecnologias de Informação e Comunicação, além de alterar comportamentos, procedimentos e hábitos em função do desenvolvimento de novas tecnologias, revolucionou

Por tecnologias da informação e comunicação entendem-se aquelas que interferem e mediam processos informacionais e comunicativos, ou seja, um conjunto de recursos tecnológicos (hardware, software e telecomunicações) integrados e direcionados para a informação e a comunicação. 
o universo do trabalho ao impor novos padrões de comportamento e concepções de organização laboral, influindo, inclusive, não apenas no conteúdo jurídico-material, mas, também, no conteúdo jurídicoprocessual trabalhista.

Todavia, se por um lado a Revolução Tecnológica possibilitou modificar o conteúdo organizacional do trabalho, criando novas demandas, novas regras de produção, sociabilidade e sobrevivência, por outro, criou novas formas de agir, de pensar e de viver. Conforme Ferreira (2009, p. 118), "para muitos, tais instrumentos mudaram tanto a maneira de nos expressarmos quanto a maneira de pensarmos, alterando profundamente nossa cultura e tornando-se elementos fundamentais a serem pautados quando pensamos sobre o futuro da humanidade".

De acordo com Manuel Castells (1999, p. 108), uma das características da tecnologia da informação é a penetrabilidade em todas as esferas da atividade humana, pois, "Como a informação é uma parte integral de toda atividade humana, todos os processos de nossa existência individual e coletiva são diretamente moldados (embora, com certeza, não determinados) pelo novo meio tecnológico". Portanto, nos novos tempos, a tecnologia não determina a sociedade, ela é a sociedade, "que não pode ser entendida ou representada sem suas ferramentas tecnológicas” (CASTELLS, 1999, p. 43).

Por isso, conferiu-se nas últimas décadas uma diversidade de estudos feitos no campo da Sociologia, da Economia, da Educação, da Saúde e da Psicologia, entre outras áreas, no sentido de aprofundar o exame dos processos de modernização técnica e organizacional (MANFREDI, 1998), que tem acompanhado o recente processo de globalização da economia capitalista e os impactos destas transformações sobre o ser humano e, evidentemente, sobre a sua relação com o trabalho.

De acordo com Kalman e Rafaeli (2007), nos últimos anos, evidenciou-se a confluência de quatro tendências: digitalização, convergência de mídias, conectividade ininterrupta e portabilidade; e, devido à facilidade e ubiquidade das tecnologias, não apenas palavras 
escritas são digitalizadas, mas também imagens, vídeos, voz e música, rompendo as fronteiras entre meio e mensagem.

Tais inovações tecnológicas não repercutiram apenas no cotidiano das pessoas, mas, também, no universo juslaboral, operando diversas transformações tanto na seara material (por exemplo, na organização do trabalho, culminando na alteração do art. $6^{\circ}$ da CLT em 2011) como na seara processual trabalhista (por exemplo, possibilitando a implantação do processo judicial eletrônico).

Segundo Machado e Goldschmidt (2014), recursos tecnológicos como as redes sociais encontram-se efetivamente presentes nas atividades laborais, permitindo, por exemplo, que empregadores exerçam seu poder de direção (através da fiscalização, do envio e do recebimento de documentos, da emissão de ordens etc.) e que empregados se organizem para pleitear melhores condições de trabalho e remuneração, bem como efetivar o agir coletivo.

Não bastasse, a popularização das redes sociais e dos aplicativos de comunicação possibilitou a publicação de conteúdos por qualquer pessoa, a um baixíssimo custo, consolidando tais recursos tecnológicos como aparatos indispensáveis para o ambiente social. Por ser, então, arena e motor das relações humanas, tais aparatos também ressignificaram o paradigma de meios de prova, conclamando os tribunais trabalhistas brasileiros a se adequarem a essa nova realidade.

Diante dessa matriz sócio-histórica, e tendo em vista a jurisprudência trabalhista brasileira, o objetivo deste artigo é examinar os impactos no Direito e no Processo do Trabalho do uso de dados obtidos em redes sociais e em aplicativos de comunicação. Considerando a impossibilidade de se contemplar a infinidade de redes sociais e aplicativos de comunicação existentes, foram eleitos os mais utilizados e conhecidos na atualidade: o Facebook e o WhatsApp.

Trata-se de uma abordagem construída a partir do método de levantamento por meio da técnica de pesquisa bibliográfica em materiais já publicados (por exemplo, doutrinas, artigos científicos, legislação, 
conteúdo disponibilizado em sítios eletrônicos e, principalmente, jurisprudência), cujos dados foram analisados através do método dedutivo.

Assim sendo, a estrutura do presente artigo compreende, inicialmente, os impactos da sofisticação tecnológica no universo do trabalho, evidenciando os novos desafios decorrentes da Revolução das Tecnologias de Informação e Comunicação no contexto juslaboral; e, por conseguinte, contempla os novos meios de prova ofertados pela sofisticação tecnológica e sua utilização no Processo do Trabalho, especialmente o Facebook e o WhatApp, considerando os efeitos jurídicos das provas produzidas através desses aparatos tecnológicos contemporâneos.

\section{Os impactos da sofisticação tecnológica no universo do trabalho: novos tempos, novos desafios}

Seria talvez estranho para a nova geração pensar que o acesso à internet, em um passado não tão distante, ocorria por meio de um acesso discado; o usuário, por meio de um computador, discava para o seu provedor, que validava o acesso para navegar na rede mundial de computadores. O acesso ocorria preferencialmente durante a madrugada, em decorrência do baixo custo das ligações nesse período do dia. E nem se cogitava baixar vídeos e músicas em qualquer formato, em razão da lentidão da transferência de dados. Por esse motivo, o acesso à internet também se restringia ao contexto empresarial.

Seria talvez estranho para a nova geração pensar que se um empregador quisesse contatar seu empregado fora da jornada de trabalho, a única possibilidade seria a contratação de um serviço de pager ou beeper; um dispositivo de comunicação mantido por uma central e individualizado por um número. Deveria o empregador contatar, por telefone, essa central, fornecer o número do aparelho destinatário e ditar a mensagem; para responder, cabia ao empregado, portador do pager, seguir o mesmo procedimento. 
Seria talvez estranho para a nova geração pensar que, há duas décadas, em decorrência da obsoleta tecnologia, o aparelho de telefone (fixo ou móvel) servia apenas à comunicação por voz, ou seja, não suportava transmissão de dados (imagens, textos, mensagens escritas, músicas, acesso à internet etc.).

No final de década de 1990, diante da privatização das empresas estatais de telecomunicação e da abertura do mercado interno para empresas estrangeiras em decorrência da globalização da economia, o Brasil trilhou um intenso período de modernização tecnológica, que não repercutiu apenas na sofisticação dos aparatos de informação e comunicação (conexões de alta velocidade e estáveis), mas também no modo de viver dos brasileiros e, principalmente, dos trabalhadores. Isso porque foi justamente essa Revolução Tecnológica que ofertou ao empregador aparatos para aprimorar a fiscalização da produtividade e da jornada de trabalho; contatar empregados a qualquer hora e em qualquer lugar; rastrear veículos da empresa; alcançar outros mercados; suprimir distâncias para o atendimento de seus consumidores; entre outras medidas.

Desta feita, atualmente as tecnologias da informação e da comunicação são empregadas maciçamente em diversas searas, incluindo o comércio (gerenciamento, publicidade, atendimento ao consumidor, e-commerce etc.), a indústria (automação), a educação (ensino-aprendizagem a distância, gestão de ensino etc.) e o setor de investimentos (por exemplo, informações e comunicação direta e em tempo real).

Todavia, em revés, foi essa mesma Revolução Tecnológica que contribuiu para que trabalhadores se ativassem fora do seu ambiente de trabalho (por exemplo, através do teletrabalho), tornando possível o labor a qualquer tempo ou, em outras palavras, instituindo a obrigação de se trabalhar todo o tempo; remontando o contexto da Revolução Industrial, quando inexistia limitação de jornada e descansos obrigatórios.

E é justamente em decorrência desse legado que a Lei $n^{\circ}$ $12.551 / 2011$ deu nova redação ao art. $6^{\circ}$ da Consolidação das Leis 
do Trabalho (CLT), cujo dispositivo passou a vigorar com o seguinte texto: "Não se distingue entre o trabalho realizado no estabelecimento do empregador, o executado no domicílio do empregado e o realizado a distância, desde que estejam caracterizados os pressupostos da relação de emprego"; e o seu parágrafo único: "Os meios telemáticos e informatizados de comando, controle e supervisão se equiparam, para fins de subordinação jurídica, aos meios pessoais e diretos de comando, controle e supervisão do trabalho alheio".

Dessa forma, para fins de controle e fiscalização, pouco importa se o empregador o faz na forma tradicional, através de controle e contato presencial, ou por meio da telemática, ensejando os mesmos resultados para a caracterização da subordinação jurídica. Se assim não fosse, a norma trabalhista deixaria à margem formas de trabalho realizadas a distância, bem como meios de registro de jornada inaugurados pela tecnologia, como o registro de ponto eletrônico e o biométrico.

No âmbito do processo do trabalho, a sofisticação tecnológica inaugurou novas perspectivas para o acesso à jurisdição através do processo judicial eletrônico, que apenas se tornou possível em razão das conexões estáveis de alta velocidade e da assinatura digital, cujas tecnologias eram impensáveis antes do final da década de 1990. A Resolução n 136/2014, do Conselho Superior da Justiça do Trabalho, instituiu o Sistema Processo Judicial Eletrônico da Justiça do Trabalho (PJe-JT) como sistema de processamento de informações e prática de atos processuais, com a promessa de facilitação e celeridade para a propositura e tramitação de ações judiciais no âmbito trabalhista, embora ainda encontre resistência de diversos operadores do Direito.

Todavia, os impactos da Revolução Tecnológica se espraiaram para além do processo judicial eletrônico, ressignificando até mesmo o entendimento de provas no contexto processual. As redes sociais e os aplicativos destinados à comunicação individual ou coletiva passaram a integrar o dia a dia das pessoas, revelando muito mais do que pretendiam ou queriam seus usuários, trazendo consigo a discussão sobre a validade e a valoração de provas extraídas dessas plataformas tecnológicas. 


\section{A tecnologia e a produção de prova no processo do trabalho}

Amauri Mascaro Nascimento (2011, p. 403) evidencia a semelhança do ofício do juiz e do historiador, "por quanto ambos tendem a averiguar como ocorreram as coisas no passado, utilizando os mesmos meios, ou seja, os rastros ou sinais que os fatos deixaram".

Conquanto o Código de Processo Civil, aplicado subsidiariamente ao processo do trabalho em decorrência do disposto no art. 769 da Consolidação das Leis do Trabalho, não a tenha conceituado, seria a prova judicial "a confrontação da versão de cada parte, com os meios produzidos para aboná-la" (NASCIMENTO, 2011, p. 419), visando à formação do convencimento do julgador. Assim sendo, não se deve confundir prova com meios de prova, embora seja comum o emprego dessas palavras como se sinônimos fossem. Todavia, meio de prova é o instrumento para se alcançar a realidade factual, ou seja, para se produzir a prova.

Importa dizer que a prova nenhum resultado produz sem a sua devida avaliação (ou apreciação) que, segundo Amauri Mascaro Nascimento (2011, p. 421), é "a operação mental que tem por fim conhecer do mérito ou valor da convicção que possa ser deduzida do seu conteúdo" e guarda dois momentos: o conhecimento, consistente no exercício da subjetividade do intérprete, e a valoração, decorrente do juízo de valor formulado a partir do objeto.

No encalço da Revolução das Tecnologias de Informação e Comunicação, os novos tempos inauguraram outros meios de prova não vislumbrados em 1973, pelo Código de Processo Civil, como, por exemplo: fotografias digitais, páginas de sítios eletrônicos, Short Message Service (SMS)2, e-mails, mensagens enviadas por aplicativos de comunicação (WhatsApp, Viber, Skype, Facebook Messenger etc.),

\footnotetext{
2 Serviço de mensagens curtas disponível em telefones móveis digitais, que permite o envio de mensagens com, no máximo, 160 caracteres.
} 
redes sociais (Facebook, Instagram, LinkedIn, MySpace, Twitter etc.), marketing digital, entre outros.

A Lei $n^{\circ} 13.105$, de 16 de março 2015, que instituiu o novo Código de Processo Civil, vigente desde 16 de março de 2016, manteve redação semelhante ao art. 332 do Código de Processo Civil de 1973. O dispositivo correspondente, qual seja, o art. 369 do novo Código de Processo Civil, também garante às partes "o direito de empregar todos os meios legais, bem como os moralmente legítimos, ainda que não especificados neste Código, para provar a verdade dos fatos em que se funda o pedido ou a defesa e influir eficazmente na convicção do juiz".

Atento às mudanças operadas pela contemporânea Revolução Tecnológica, o novo Código de Processo Civil agasalhou a ata notarial como meio de prova, assim dispondo em seu art. 384: "A existência e o modo de existir de algum fato podem ser atestados ou documentados, a requerimento do interessado, mediante ata lavrada por tabelião". O parágrafo único do citado dispositivo ainda permite que dados representados por imagem ou som gravados em arquivos eletrônicos constem da ata notarial.

Por ata notarial entende-se "o instrumento público pelo qual o tabelião, ou preposto autorizado, a pedido de pessoa interessada, constata fielmente os fatos, as coisas, pessoas ou situações para comprovar a sua existência, ou o seu estado" (FERREIRA; RODRIGUES, 2010, p. 112). Para João Teodoro da Silva (2010, p. 33), é "uma das espécies do gênero instrumento público notarial, por cujo meio o tabelião de notas acolhe e relata, na forma legal adequada, fato ou fatos jurídicos que ele vê e ouve com seus próprios sentidos", podendo ser fatos naturais ou humanos, desde que esses últimos não constituam negócio jurídico. $E$, segundo José Antonio Escartin Ipiens (1952, p. 176), é o:

Instrumento público autorizado por notário competente, a requerimento de uma pessoa com interesse legítimo e que, fundamentada nos princípios da função imparcial e independente, pública e responsável, tem por objeto constatar a realidade ou verdade de um fato que o notário 
vê, ouve ou percebe por seus sentidos, cuja finalidade precípua é a de ser um instrumento de prova em processo judicial, mas que pode ter outros fins na esfera privada, administrativa, registral, e, inclusive, integradores de uma atuação jurídica não negocial ou de um processo negocial complexo, para sua preparação, constatação ou execução.

Em outras palavras, trata-se de um instrumento público por meio do qual o notário, ou pessoa por ele designada, procede ao registro de fatos jurídicos suscetíveis de consequências jurídicas, captando, por seus sentidos, elementos da situação que serão traslados para livros de notas ou outro documento público, a fim de se tornar prova em processo judicial ou prevenir a formação de conflito. Explica Oscar Vallejo Yanez (1973, p. 639):

O poder certificante do notário é uma faculdade que a lei lhe dá para, com sua intervenção, evitar o desaparecimento de um fato antes que as partes o possam utilizar em proveito de suas expectativas. A fé pública é, em todo o momento do negócio jurídico, o caminho mais efetivo para a evidência [...]. Tudo se reduz à intervenção notarial que, com sua presença ou sua atuação, soleniza, formaliza e dá eficácia jurídica ao que ele manifesta ou exterioriza no instrumento público, seja este escriturado ou não. Isto se relaciona, também, com o poder certificante do notário, o que permite às partes em forma voluntária, escolher a forma e o modo de resolver seus negócios [...]; neste caso, como afirma Gatán, a função notarial pode considerar-se como jurisdicional. $O$ notário, dentro de sua ampla gama de faculdades, logrará, com sua intervenção, estabelecer a prova pré-constituída, que há de servir de pauta legal, no momento em que seja necessário solicitá-la.

Diante dessa funcionalidade, são diversas as modalidades de ata notarial: ata notarial de presença e declaração; de notoriedade; de nomeação de tutor; de declaração de estado civil; de declaração de dependência econômica; entre outras. Contudo, tendo em vista a presente abordagem, destaca-se a ata notarial de verificação de 
atos e fatos na rede mundial de computadores ou em aplicativos de comunicação.

Nessa modalidade de ata notarial, "o tabelião acessa determinado endereço na rede mundial de computadores e verifica o conteúdo de certo sítio (página ou site), materializando tudo aquilo que presenciou e certificando não só o conteúdo existente, mas também a data e horário de acesso", podendo ou não imprimir a imagem da página acessada no próprio instrumento notarial (TOMASZEWSKI , 2008, p. 15-16). Ou, ainda, o tabelião verifica e certifica um fato, podendo ser, por exemplo, uma imagem, um diálogo ou uma confissão registrada em um aparelho celular, em razão do envio ao destinatário por meio de um aplicativo de comunicação ou de SMS; nesse caso, o tabelião verifica a mensagem no próprio aparelho celular, certificando o conteúdo, a origem, a data e hora, entre outros elementos essenciais.

É certo que a ata notarial, como instrumento de prova, não é nenhuma novidade no contexto jurídico, haja vista que a Lei Federal $n^{\circ} 8.935 / 94$ já a previa em seus artigos $6^{\circ}$ e $7^{\circ}$, como atribuição do tabelião de notas visando à autenticação de fatos.

Contudo, em um cotidiano deveras telemático, haja vista que em 2014 o país já contava com 277 milhões de linhas ativas de telefonia móvel, curioso seria se o novo Código de Processo Civil ignorasse tal realidade, deixando de elencar a ata notarial dentre os instrumentos probatórios. Isso porque, na atualidade, diversos são os fatos que ocorrem e são registrados nas malhas virtuais, razão pela qual a ata notarial, antes mesmo do novo Código de Processo Civil, alcançou expressiva importância para conferir autenticidade a mensagens e informações (textos e áudio) gravadas em telefones móveis ou ostentadas em sítios eletrônicos, e-mails ou redes sociais.

Todavia, no âmbito do Processo do Trabalho, a adoção desse meio probatório é escassa, tanto em razão da hipossuficiência econômica do trabalhador para custear os emolumentos notariais, como em decorrência do disposto no art. 456 da Consolidação das Leis do Trabalho e do Princípio da Simplicidade, que igualam a ata notarial a outros meios 
digitais lícitos (por exemplo, fotografia, print screen, acesso, áudio etc.), com menos custo ao trabalhador.

Ainda na senda do novo Código de Processo Civil, o parágrafo $1^{\circ}$ do art. 422 também prevê a aptidão das fotografias digitais e das extraídas da rede mundial de computadores para provar as imagens que reproduzem; e a Seção VIII, “Dos Documentos Eletrônicos”, prevê regras para a utilização de documentos eletrônicos no processo convencional, bem como para a apreciação pelo juiz de seu valor probante (artigos 439 a 441).

O fato é que há muito o Direito e o Processo do Trabalho têm se apropriado das transformações tecnológicas, impondo inúmeros desafios às partes e ao julgador, sendo certo que, diante das mudanças factuais apontadas, "o direito do trabalho deve se adaptar ao mundo de hoje, que não é mais o mesmo de quando foi concebido" (SILVA, 2005, p. 102), embora seja sabida a dificuldade de se acompanhar o dinamismo das mudanças sociais.

\section{O WhatsApp como meio de prova no Processo do Trabalho}

De acordo com o sítio eletrônico institucional do aplicativo, "o WhatsApp Messenger é um aplicativo de mensagens multiplataforma que permite trocar mensagens pelo celular, sem pagar por SMS", utilizando-se do plano de dados do usuário. Permite o aplicativo, além do envio de mensagens de texto, a criação de grupos e o envio, ilimitado, de imagens, vídeos e áudios (WHATSAPP, 2015).

Nos últimos tempos, não são raros os autos - físicos ou eletrônicos - de processos trabalhistas que ostentam em suas páginas imagens de telas do WhatsApp, a fim de comprovar, por exemplo, a justa causa praticada por um empregado ou o ato discriminatório impingido pelo empregador em desfavor de um de seus empregados.

Acompanhando os novos tempos, a Justiça do Trabalho de Campinas adotou o WhatsApp para que trabalhadores e empresas se 
conciliem através do aplicativo, do qual participam os advogados, um servidor público no papel de mediador e o magistrado (ROMANI, 2015).

Em recente e pioneiro caso, Ney Maranhão, magistrado da $1^{\text {a }}$ Vara do Trabalho de Tucuruí (PA), diante da inércia e do silêncio do Réu, residente no exterior, procedeu com a notificação da publicação da sentença através do aplicativo, cuja constatação da ciência fora certificada em razão da sinalização pelo aplicativo da leitura do conteúdo da mensagem, conforme se observa no seguinte recorte:

CERTIFICO que, [...] dei ciência de todo o teor da sentença ao reclamado, [...], via mensagem, utilizando o recurso tecnológico WhatsApp. Para se adequar a tal recurso e facilitar a leitura, dividi o texto em partes, enviando-o a ambos os destinatários. Às 12:46hs desta mesma data, foi feita a leitura da mensagem pela esposa do reclamado, e às 19:06hs a leitura foi feita pelo próprio reclamado, conforme cópias da parte final de cada texto(anexa)extraídas do celular deste oficial, as quais, contém data e hora exatas do recebimento e da leitura feita pelos destinatários. Ressalto que apenas a última parte da sentença, cálculos de liquidação, até o presente momento, não foi lida pelo reclamado, embora também enviada ao seu WhatsApp, mas foi lida por sua esposa. Diante do exposto, devolvo o presente expediente para apreciação deste juízo, colocandome, desde já, á disposição, para futuras diligências. O afirmado é verdade, dou fé. (BRASIL, 2015c).

Em outro caso tramitado perante o Tribunal Regional do Trabalho da $5^{\text {a }}$ Região, Bahia, buscava o empregado a reversão da justa causa em razão de falta coletiva ao serviço (20 empregados), previamente arquitetada com outros trabalhadores através de um grupo denominado "macete zapzap", criado no aplicativo WhatsApp, conforme se extrai do respectivo acórdão regional:

No curso da sobredita investigação, informa ainda o Réu, que fora apurada a existência de um grupo denominado 'macete zapzap', criado na rede social Whatsapp, formado por alguns empregados, inclusive o Autor, através do qual 
organizaram, nas palavras do Demandado, uma espécie de 'rebelião', planejando uma falta coletiva para o dia 04/06/2014. Buscaram, assim, atendimento junto a uma clínica conveniada ao SUS, objetivando garantir atestados médicos que respaldassem suas faltas. Nesse passo, teriam trocado informações sobre a quantidade de dias de afastamento que cada um conseguia, na medida em que eram atendidos, sugerindo, segundo o Recorrido, uma espécie de competição entre os componentes do grupo, sobre quem teria maior poder de convencimento sobre o médico que os atendia. (BRASIL, 2015b).

Diante da comprovação dos fatos, a $3^{a}$ Turma do Tribunal Regional do Trabalho da $5^{a}$ Região manteve a decisão de origem, confirmando a justa causa aplicada ao empregado-reclamante.

Também em decorrência do uso impróprio do aplicativo, em julho de 2014, uma enfermeira foi demitida por justa causa por ter filmado e divulgado, através de seu celular, o jogador de futebol Neymar adentrando a sala de emergência de um hospital de Fortaleza. Com vinte e seis segundos de duração, o vídeo exibe o jogador sendo transportado em uma maca pelos corredores do hospital até a sala de emergência, cujo registro é finalizado com um sorriso e um beijo da enfermeira. Em pouco tempo, o vídeo, espalhado para vários grupos do WhatsApp, também podia ser visto em vários canais do YouTube e pelo Facebook (UOL COPA, 2014) ${ }^{3}$.

Em outra situação, a $1^{\text {a }}$ Câmara do Tribunal Regional do Trabalho da $12^{a}$ Região, Santa Catarina, condenou uma loja de artigos esportivos a indenizar uma empregada, em $\mathrm{R} \$ 13$ mil, em razão de assédio moral praticado por um de seus supervisores através do aplicativo WhatsApp. Em mensagens compartilhadas diariamente no grupo de empregados mantido no aplicativo, o supervisor a chamava de "gorda", "feia" e

3 A esse fenômeno dá-se o nome de viral, cujo termo, uma derivação sufixal da palavra "vírus", significa a divulgação e o reconhecimento massivo, em um curto espaço de tempo, pela mídia e pelo público. 
"bigoduda", dentre outros apelidos pejorativos relacionados a aspectos físicos da empregada. De acordo com o voto do desembargador Garibaldi Tadeu Pereira Ferreira, acompanhado por unanimidade, "A autora foi exposta a frequentes e repetitivos atos atentatórios a sua dignidade, que lhe causaram danos psicológicos e tinham o objetivo de coagi-la a pedir demissão" e, consoante aos argumentos do julgador de primeira instância, "embora a autora não fosse ofendida perante clientes, as ofensas diárias por ato do gerente da empresa, degradando o ambiente de trabalho, fez com que a empregada se sentisse humilhada e rebaixada perante os demais colegas de trabalho" (BRASIL, 2015a).

Em outro exemplo, a $3^{\text {a }}$ Turma do Tribunal Regional do Trabalho

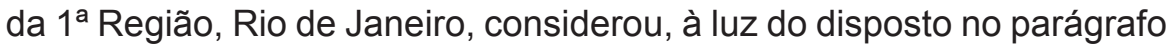
único do art. $6^{\circ}$ da Consolidação das Leis do Trabalho, que o controle da jornada de trabalho através de ferramentas modernas (como o WhatsApp), dirigido a empregados que exercem atividade externa, afasta a aplicabilidade do disposto no art. 62, inciso I, da Consolidação das Leis do Trabalho, conforme a seguir exposto:

Caso seja possível o controle do horário de trabalho, seja por meio de roteiros pré-estabelecidos, da entrega de relatórios pelos trabalhadores ao término da prestação de serviços, uso de instrumentos telemáticos e informatizados, como telefone, tablet, computadores, pager, bip, inclusive, com o emprego de ferramentas modernas como o uso do Skype, Whatsapp, MSN, redes sociais, não pode simplesmente o sujeito empresarial abster-se de fazê-lo, com o desiderato de não arcar com o pagamento da sobrejornada, em total desrespeito aos direitos fundamentais trabalhistas específicos. (BRASIL, 2014a).

Nessa mesma linha, com fundamento no parágrafo único do art. $6^{\circ}$ da Consolidação das Leis do Trabalho, se o empregado, rotineiramente e fora da jornada laboral, responder a questionamentos, discutir estratégias, prestar esclarecimentos, participar de conferências e planejamentos de trabalho através do WhatsApp, com seu empregador, superior hierárquico ou grupo de empresa, estará, portanto, ativando-se extraordinariamente. 
A ele caberá o direito ao correspondente pagamento (ou, se for o caso, à compensação), nos termos dos art. 59 da Consolidação das Leis do Trabalho, cumulado com o art. $7^{\circ}, \mathrm{XVI}$, da Constituição Federal. O registro das mensagens pelo aplicativo garantirá a produção de prova judicial em favor dos interessados, caso seja necessário.

Assim sendo, a utilização dessas modernas tecnologias no contexto laboral desencadeia diversas consequências para todos aqueles que nele se encontram, razão pela qual é preciso fixar regras para a utilização e antever os seus desdobramentos, que, tantas vezes, vão muito além da real finalidade desses aparatos tecnológicos (FERREIRA, 2015).

Por outro lado, o mau uso desse aplicativo pode culminar em punições em desfavor do empregado, desde advertência verbal até a pena mais grave prevista no Direito do Trabalho, a dispensa motivada ou por justa causa.

À guisa de exemplo, o empregado que causar prejuízo ao seu empregador (à produtividade, ao regular desenvolvimento de tarefas etc.) em decorrência do uso do WhatsApp para assuntos alheios à atividade, durante a jornada de trabalho, poderá incorrer em justa causa por desídia, nos termos do art. 482, e, da Consolidação das Leis do Trabalho. Ainda, o empregado que divulgar segredo empresarial por meio de imagem, mensagem, vídeo ou áudio transmitido pelo WhatsApp, poderá sofrer dispensa por justa causa, consoante ao previsto na alínea $g$, do art. 482 da Consolidação das Leis do Trabalho; e, se a divulgação for endereçada para a concorrência, poderá caracterizar ato de concorrência, cuja conduta também se traduz em justa causa, conforme dispõe a alínea $c$ do mesmo dispositivo celetista. E, por fim, o envio ou compartilhamento pelo empregado de imagem, mensagem, vídeo ou áudio com conteúdo lesivo da honra ou boa fama de outros empregados ou do seu empregador, pode também caracterizar justa causa, consoante às alíneas $j$ e $k$, respectivamente, do art. 482 da Consolidação das Leis do Trabalho.

Salienta-se, ainda, que tais desdobramentos não se limitam ao mau uso apenas do WhatsApp, mas, também, ao uso inconsequente 
de outros aplicativos assemelhados, como, por exemplo, Viber, Skype e Facebook Messenger, além de SMS e e-mail.

Por isso, é importante que o empregador, ao se utilizar ou liberar o uso dessa ferramenta no contexto laboral, cuja funcionalidade não se discute nos dias de hoje, estabeleça políticas para a sua utilização, evitando prejuízos patrimoniais e extrapatrimoniais para todos os protagonistas desse cenário e zelando pelo equilíbrio do meio ambiente do trabalho, que a todos compete, conforme preveem os artigos 225 e 200, VIII, da Constituição Federal.

\section{Facebook como meio de prova no Processo do Trabalho}

As redes sociais surgiram no encalço da Revolução das Tecnologias de Informação e Comunicação, com a popularização da internet a partir dos anos 2000, e, atualmente, já fazem parte da rotina de milhares de pessoas no Brasil. Decorreram da evolução de serviços de socialização de dados, propiciados pelo desenvolvimento da tecnologia dial-up, em 1969, do envio do primeiro e-mail, em 1971, e da criação, sete anos mais tarde, do Bulletin Board System - sistema criado em Chicago para convidar pessoas para eventos e divulgar anúncios pessoais (DAQUINO, 2012).

Em 1985, a America Online criou uma ferramenta para que usuários criassem perfis virtuais, através dos quais podiam se descrever e criar comunidades para o intercâmbio de informações e discussões sobre os mais variados assuntos. Doze anos depois, a empresa implementou um sistema de mensagens instantâneas que, mais tarde, inspiraria a criação dos serviços (chats) e aplicativos de comunicação (DAQUINO, 2012).

Desde então, surgiram os primeiros "protótipos" das redes sociais, com o lançamento do GeoCities, em 1994; do Fotolog, em 2002; do LinkedIn, voltado para contatos profissionais, e do MySpace, em 2003; do Flickr e do Orkut, em 2004; e do Facebook que, embora criado em 2004, apenas chegou ao público no ano de 2006. 
O Facebook é a rede social mais usada atualmente e tem como funcionalidade a troca de mensagens, informações e o compartilhamento de arquivos de imagem, áudio, vídeo, documentos e links. Criada pelos americanos Mark Zuckerberg, Dustin Moskovitz, Chris Hufghes, e pelo brasileiro Eduardo Saverin, essa ferramenta de relacionamento virtual também possibilita a divulgação de páginas comerciais, razão pela qual é utilizada por muitas empresas para divulgar produtos, prestar atendimento a clientes, coletar e responder críticas, sugestões ou solicitações de informação.

Em balanço recentemente divulgado, relacionado ao último trimestre de 2014, o Facebook contabilizou 1,39 bilhão de usuários ativos e receita de US $\$ 3,85$ bilhões. Além disso, a empresa controla mais dois aplicativos extremamente populares, o Instagram e o WhatsApp (FOLHA DE SÃO PAULO, 2015).

Primeiramente, importa esclarecer que, em regra, ao uso do Facebook no contexto juslaboral também se aplica a mesma lógica anteriormente desenvolvida. Significa dizer que, o mau uso desse recurso tecnológico pode culminar tanto em prejuízos para o empregador como em punições para o empregado (desde advertência verbal até a mais grave sanção trabalhista, a justa causa).

Não são raros os autos de processos trabalhistas que ostentam em suas páginas, físicas ou digitais, telas recuperadas, printadas ou impressas da aludida rede social. A situação mais recorrente na atualidade é a contradita de testemunha que figura no Facebook do autor da ação trabalhista e vice-versa. Isso porque, consoante à regra prescrita no art. 405, parágrafo $3^{\circ}$, inciso III, do Código de Processo Civil de 1973, são suspeitas aquelas pessoas que mantenham amizade íntima com o autor da ação, razão pela qual não podem depor como testemunhas. Vale dizer que o novo Código de Processo Civil de 2015 manteve a mesma regra em seu art. 447 , parágrafo $3^{\circ}$, inciso $1^{4}$.

\footnotetext{
4 O novo Código de Processo Civil excluiu do rol de suspeitos o condenado por crime de falso testemunho, mediante trânsito em julgado da sentença, e o que, por seus costumes, não for digno de fé.
} 
Por amigo íntimo entende-se aquele que mantém convivência com o autor da ação fora do contexto laboral, compartilhando momentos de alegria, de angústia e diversas situações da vida (por exemplo, casamento, aniversário, viagens de férias, apadrinhamento de casamento e de filhos, recreação durante finais de semana etc.). O traço essencial para a caracterização de amizade íntima é a existência de uma relação de afeição e confiança.

Ocorre que, com o passar dos tempos, as redes sociais assumiram nova conotação, haja vista que não mais são utilizadas entre pessoas que já se conhecem e se relacionam fora do ambiente virtual; pelo contrário, muitos usuários conservam em sua lista de amigos pessoas que jamais viram, quanto menos se falaram pessoalmente; ou pessoas que viram poucas vezes; ou, ainda, pessoas que viram uma única vez e não mais se falaram novamente, embora seguissem conectadas pelo Facebook. Isso sem considerar pessoas que possuem centenas ou milhares de amigos virtuais apenas para alcançar certa popularidade num universo paralelo, o virtual, não sendo razoável se crer que seja possível centenas ou milhares de pessoas se frequentarem como amigos íntimos. Nesse sentido, têm-se os seguintes entendimentos jurisprudenciais:

CONTRADITA - TESTEMUNHA MANTÉM A AUTORA EM SEU PERFIL DE AMIGOS DO FACEBOOK. O Facebook é uma rede social, de utilização gratuita, onde os usuários criam seus perfis com fotos e listas de interesses, com possibilidade de troca de mensagens públicas e privadas entre eles próprios e os participantes de um grupo de amigos. Essa rede social permite que o usuário, comumente, tenha muitos amigos em seu perfil - centenas, inclusive -, sem que com estes possua contato estreito e íntimo. Sendo assim, entendo que o simples fato de a testemunha possuir a autora em seu grupo de amigos do facebook, de per si, não configura a amizade íntima prevista no art. 405 , parágrafo $3^{\circ}$, III, do CPC. Isso porque a amizade íntima apta a configurar a suspeição para depor em juízo caracteriza-se pelo relacionamento social que ultrapassa o âmbito da relação de emprego e evidencia a convivência íntima, estreitamente ligada por afeição e confiança. Não 
configurada essa hipótese, o indeferimento da contradita é medida que se impõe. Recurso ordinário da reclamada a que se nega provimento, neste aspecto (BRASIL, 2013).

NULIDADE DA PROVA TESTEMUNHAL. AMIZADE NO FACEBOOK. PRELIMINAR REJEITADA. O fato de a reclamante figurar no 'facebook' das testemunhas e viceversa, por si só, não significa amizade íntima, pois é de conhecimento geral que as pessoas se 'adicionam' nos contatos das redes sociais, sem, necessária e efetivamente, terem convivência íntima. Com efeito, tal circunstância, isoladamente, não sugere que as testemunhas tenham interesse em beneficiar a reclamante. Preliminar rejeitada. (BRASIL, 2014d).

Conforme já consolidado pela jurisprudência pátria, "A simples comunicação entre pessoas na rede social conhecida como Facebook não pode ser tida como amizade íntima, haja vista que o ser humano é, por si mesmo, sociável, ou seja, busca conviver com outros e não se isolar" (BRASIL, 2014b). Outra situação extremamente recorrente é a utilização de perfis mantidos no Facebook para impugnar requerimento do benefício de justiça gratuita, com o intuito de evidenciar ter o demandante efetivas condições de arcar com as despesas processuais.

A Seção Especializada em Execução do Tribunal Regional do Trabalho da $4^{a}$ Região, Rio Grande do Sul, em sede de Agravo de Petição interposto pela demandante em razão de indeferimento da benesse da justiça gratuita, deu provimento ao recurso, isentando-a das despesas processuais. A demandada-exequente anexou à contraminuta documentos supostamente colhidos do Facebook, aduzindo ter a demandante-executada intensa vida social, emprego público junto ao Ministério Público e ser proprietária de veículo automotor. Prevaleceu o voto divergente do desembargador Wilson Carvalho Dias, nos seguintes termos:

BENEFÍCIO DE JUSTIÇA GRATUITA. INFORMAÇÕES COLHIDAS NAS REDES SOCIAIS. Inviável embasar a não concessão do benefício de justiça gratuita em informações colhidas do perfil da agravante constante do Facebook, à 
revelia do seu conhecimento e sem que seja possível sequer verificar a fonte de sua obtenção, devendo prevalecer a declaração de pobreza firmada pela parte. Agravo de petição provido. (BRASIL, 2012).

Entendeu o Tribunal Regional do Trabalho da $4^{\text {a }}$ Região ser caso de dispensa do pagamento das custas processuais, considerando a presunção de veracidade que possui a declaração de miserabilidade, possível de ser juntada aos autos em qualquer fase processual, bem como o fato de não ser possível embasar o indeferimento do benefício em informações colhidas de um perfil Facebook, à revelia do conhecimento do usuário demandante. Consignou, ainda, que a suposta obtenção de tais documentos ocorreu por via duvidosa, sem autorização da demandante, por não haver referência ao localizador de recursos uniforme (Uniform Resource Locator - URL), que permitiria verificar a fonte, "mormente porque, como se bem sabe, há inúmeros relatos de criação por terceiros de perfis falsos nas redes sociais” (BRASIL, 2012).

Desta feita, embora exista caudalosa possibilidade de constituição de prova por meio de ambientes virtuais, é certo que alguns cuidados devem ser observados, incluindo a indicação da fonte do documento, imagem, áudio ou vídeo, a fim de garantir a autenticidade e, por corolário, a validade das informações. Observadas tais formalidades e a oportunidade para o contraditório, é evidente que perfis do Facebook podem contribuir para a comprovação de fatos do dia a dia que guardem relação com a discussão processual.

Por fim, tal como se aplica ao WhatsApp, não são raros os casos de utilização do Facebook como meio para comprovar fato caracterizador de dispensa por justa causa ou para desconstituí-la. A $8^{a}$ Turma do Tribunal Regional do Trabalho da $4^{\text {a }}$ Região manteve a decisão do juízo de primeiro grau, que confirmou a justa causa para o despedimento de uma empregada que teria ofendido sua superior hierárquica por meio de postagem no Facebook, incorrendo na alínea $b$ do art. 482 da Consolidação das Leis do Trabalho, conforme a seguir transcrito:

RECURSO ORDINÁRIO DA RECLAMANTE. AGENTE 
COMUNITÁRIO DE SAÚDE. MAU PROCEDIMENTO. JUSTO MOTIVO PARA O DESPEDIMENTO. Atendendo ao disposto na Lei 11.350/06, o Município reclamado justificou a despedida da reclamante - agente comunitário de saúde - aduzindo caracterizada a hipótese de mau procedimento. Considerando que a reclamante não nega postagem no facebook que teria ofendido sua superior hierárquica, limitando-se a negar a gravidade do fato, impõe-se manter a sentença de improcedência proferida pelo Juízo de primeiro grau (BRASIL, 2014e).

A imputação de mau procedimento teria decorrido da atuação da reclamante nas redes sociais, quando teria chamado sua superior hierárquica de "vaca", o que não foi objeto de negativa da trabalhadora, cujo fato inviabilizou o convívio entre as partes e caracterizou o justo motivo para o despedimento.

E, em outro caso, a $10^{\mathrm{a}}$ Turma do Tribunal Regional do Trabalho da $2^{a}$ região, São Paulo, também confirmou o justo motivo para o despedimento de uma trabalhadora que havia ofendido seu superior hierárquico e o sócio da empresa através de postagens no Facebook. Conforme o conteúdo registrado na ata notarial apresentada pela demandada e reconhecido como autêntico pela demandante, a trabalhadora desferiu inúmeros comentários grosseiros e desrespeitosos a seus superiores e à pessoa do sócio da demandada, incorrendo no disposto nas alíenas $b$ (incontinência de conduta ou mau procedimento), $h$ (ato de indisciplina ou de insubordinação) e $k$ (ato lesivo da honra ou da boa fama ou ofensas físicas praticadas contra o empregador e superiores hierárquicos), do art. 482 da Consolidação das Leis do Trabalho. Ademais, em uma das postagens, a demandante confessou ter deixado de trabalhar sem qualquer motivo justificável (para assistir uma novela), deixando, pois, de cumprir suas obrigações contratuais, resultando na seguinte decisão regional:

DA JUSTA CAUSA. In casu, as faltas graves cometidas pela reclamante restaram comprovadas, à saciedade, por meio dos prints da páginas da rede social Facebook, cujos conteúdos foram registrados no $5^{\circ}$ Tabelionato de 
Notas de Santo André e reconhecidos como autênticos pela reclamante em audiência, de modo a confirmar a tese da reclamada. Não bastasse relatar agressividade em relação ao seu superior hierárquico (encarregado), a reclamante também publicou comentários ofensivos à pessoa do sócio da reclamada, o que configura as condutas previstas nas alíneas h e k do 482 da CLT. Importante registrar que os comentários feitos pela reclamante eram veiculados em rede social de acesso público, tanto que a ré tomou conhecimento deles através de seu cliente, fato este não impugnado pela autora. Valendo-se, ainda, de sua página na rede social Facebook, a reclamante alardeava a sua intenção de apresentar atestados para justificar as faltas ao trabalho, o que caracteriza a conduta da alínea $b$ do dispositivo acima citado. Em nada altera tal conclusão a alegação de que a reclamante não teria ciência do ato faltoso que ensejou a dispensa por justa causa, máxime diante do 'aviso prévio do empregador', cuja assinatura se recusou a autora a apor, que elenca as alíneas $b, h$ e $k$ do art. 482 da CLT e do conteúdo dos comentários da autora na rede social. Nego provimento.

Da reconvenção - dano moral. Verifica-se que a autora ofendeu a honra objetiva da reclamada ao publicar na rede social Facebook que esta estava quase falindo, não se podendo olvidar que, conforme narrado pela ré, tomou conhecimento dos comentários da autora através de sua cliente, circunstância que corrobora a alegação da reclamada de que teve a sua imagem e boa fama violadas. Destarte, mantenho a r. sentença, ainda que por diverso fundamento. (BRASIL, 2014c).

Rebatendo a tese de defesa da demandante, o Tribunal Regional da $2^{a}$ Região ainda asseverou que, em razão da gravidade das ofensas, sobretudo por dizer na rede social que a empresa estava beirando a falência, a atitude da trabalhadora sequer poderia ser acalentada pelo direito constitucional à liberdade de expressão, haja vista que tal alegação exige prova de veracidade, sob pena de caracterizar difamação, nos termos do art. 139 do Código Penal. 
Diante do exame proposto, evidencia-se que as redes sociais, antes entendidas como um universo paralelo, impactaram sobremaneira na vida das pessoas e, consequentemente, no universo laboral, operando desdobramentos talvez impensáveis quando inventadas. E é justamente essa confluência de duas existências, fora e dentro da "realidade" virtual, que tem desafiado o Direito e o Processo do Trabalho, que mais uma vez são compelidos a se readaptarem diante de uma sociedade que se reinventa e reinventa suas necessidades de tempo em tempo.

\section{Conclusão}

Se por um lado a Revolução das Tecnologias de Informação e Comunicação possibilitou modificar o conteúdo organizacional do trabalho, criando novas demandas, novas regras de produção, sociabilidade e sobrevivência, por outro, criou novas formas de agir, de pensar e de viver. Por essa razão, nas últimas décadas, diversas áreas do conhecimento têm se debruçado para estudar os impactos dos processos de modernização técnica e organizacional sobre o ser humano e, evidentemente, sobre a sua relação com o trabalho.

Isto porque, a mesma tecnologia que tornou possíveis facilidades como, por exemplo, o processo digital, também foi responsável pela aceleração do ritmo laboral, pela instituição de novos meios de prova, pela intensa e prolongada conexão do trabalhador com o trabalho e pela possibilidade de uma existência virtual em um universo paralelo que a todos desafia.

A utilização dessas modernas tecnologias no contexto laboral, incluindo recursos tecnológicos como o Facebook e o WhatsApp, desencadeia diversas consequências para todos aqueles que nele se encontram. Como meios de prova, de acordo com o recorte desenvolvido, são ferramentas extremamente funcionais, desde que sejam cumpridas as formalidades asseveradas pela jurisprudência, conforme demonstrado. Por isso, é preciso fixar regras para a utilização desses recursos tecnológicos, antevendo os desdobramentos decorrentes, os 
quais, tantas vezes, vão muito além da real finalidade para a qual foram criados.

Em razão do dinamismo social e da incontrolável capacidade humana de se transformar e de reinventar o seu entorno, em alguns anos, ou décadas, tais reflexões já serão obsoletas, porque a tecnologia, por razões óbvias, caminha na velocidade da luz se comparada à capacidade do Direito em se adequar às mudanças sociais, haja vista se tratar de uma ciência póstuma. Todavia, o ser humano mais uma vez se reinventará e encontrará novos desafios albergados pela inquietação consigo e com o seu mundo, fruto da sua própria condição humana, os quais certamente exigirão que o Direito e o Processo do Trabalho se reinventem e se adéquem a outras necessidades.

\section{Referências}

ALMEIDA, Victor Hugo de. Consumo e trabalho: impactos no meio ambiente do trabalho e na saúde do trabalhador. 2013. $241 \mathrm{f}$. Tese (Doutorado em Direito) - Faculdade de Direito, Universidade de São Paulo, São Paulo, 2013.

BRASIL. Tribunal Regional do Trabalho da $12^{\mathrm{a}}$ Região, Santa Catarina. Acórdão. Recurso Ordinário nº 2421-48.2014.5.12.0022. $1^{\text {a }}$ Turma. Dano moral. Configuração. Relator Des. Garibaldi Tadeu Pereira Ferreira. Diário Oficial do Estado, Santa Catarina, 20 fev. 2015a. Disponível em: <http://consultas.trt12.jus.br/SAP2/DocumentoListar.do ?pidDoc=294295\&plocalConexao=sap2\&ptipo=PDF>. Acesso em: 10 abr. 2015.

. Tribunal Regional do Trabalho da $1^{\text {a }}$ Região, Rio de Janeiro. Acórdão. Recurso Ordinário $n^{\circ}$ 0006400-73.2008.5.01.0009. $7^{a}$ Turma. Horas extras. Labor externo gerente de contas. Controle da jornada. Relatora Des. Sayonara Grillo Coutinho Leonardo da Silva. DEJT, Rio de Janeiro, 11 set. 2014a. Disponível em: <http://www.trt1. jus.br/trt-consultaprocessual-portlet/DocumentoServlet?sqDocumen to $=47655724>$. Acesso em: 10 abr. 2015. 
. Tribunal Regional do Trabalho da $2^{\mathrm{a}}$ Região, São Paulo. Acórdão. Recurso Ordinário nº 0001332-41.2012.5.02.0441. 18 ${ }^{a}$ Turma. Contradita - Testemunha mantém a autora em seu perfil de amigos do Facebook. Relatora Des. Maria Cristina Fisch. DEJT, São Paulo, 23 jul. 2013. Disponível em: <http://aplicacoes1.trtsp.jus.br/ vdoc/TrtApp.action?getEmbeddedPdf=\&id=608037>. Acesso em: 10 abr. 2015.

. Tribunal Regional do Trabalho da $2^{a}$ Região, São Paulo. Acórdão. Recurso Ordinário nº 0003089-84.2012.5.02.0016. $3^{a}$ Turma. Testemunha contraditada por amizade íntima - Rede social. Relatora Des. Rosana de Almeida Buono. DEJT, São Paulo, 23 set. 2014b. Disponível em: <http://aplicacoes1.trtsp.jus.br/vdoc/TrtApp.action?getE mbeddedPdf=\&id=2472608> . Acesso em: 8 abr. 2015.

. Tribunal Regional do Trabalho da $2^{\mathrm{a}}$ Região, São Paulo. Acórdão. Recurso Ordinário $n^{\circ} 0002680-78.2013 .5 .02 .0435 .10^{a}$ Turma. Da justa causa. Relatora Marta Casadei Momezzo. DEJT, São Paulo, 28 ago. 2014c. Disponível em: <http://aplicacoes1.trtsp.jus.br/ vdoc/TrtApp.action?getEmbeddedPdf=\&id=2305795>. Acesso em: 8 abr. 2015.

. Tribunal Regional do Trabalho da $3^{a}$ Região, Minas Gerais. Acórdão. Recurso Ordinário nº 0001180-57.2013.5.03.0076. Turma Recursal de Juiz de Fora. Nulidade da prova testemunhal. Amizade no Facebook. Preliminar rejeitada. Relator Heriberto de Castro.

DEJT, São Paulo, 24 jul. 2014d. Disponível em: <http://as1.trt3.jus.br/ consulta/detalheProcesso1_0.htm?conversationld=5651394\#>. Acesso em: 8 abr. 2015.

- Tribunal Regional do Trabalho da $4^{a}$ Região, Rio Grande do Sul. Acórdão. Agravo de Petição nº 0000518-23.2011.5.04.0016. Seção Especializada em Execução. Benefício de justiça gratuita. Informações colhidas nas redes sociais. Relator Wilson Carvalho Dias. DEJT, Rio Grande do Sul, 21 nov. 2012. Disponível em: <http://www.trt4.jus.br/ consulta-processual-portlet/servlet/download.html?tipo=complemento \&processo $=0000518-23.2011 .5 .04 .0016 \&$ chave $=1343055584 \mathrm{~K} 4184 \mathrm{X}$ \&andamento=44066261\&ordem=1\&data=2012-11-13\&origem=TRT > . Acesso em: 8 abr. 2015. 
- Tribunal Regional do Trabalho da $4^{a}$ Região, Rio Grande do Sul. Acórdão. Recurso Ordinário nº 0000356-84.2013.5.04.0201. $8^{a}$ Turma. Recurso ordinário da reclamante. Agente comunitário de saúde. Mau procedimento. Justo motivo para o despedimento. Relator Juraci Galvão Júnior. DEJT, Rio Grande do Sul, 21 maio 2014e. Disponível em: <http://www.trt4.jus.br/consulta-processual-portlet/ servlet/download.html?tipo $=$ complemento\&processo $=0000356-$ 84.2013.5.04.0201\&chave $=1342809171 \mathrm{~K} 6768$ X\&andamento $=4978056$ 1\&ordem=1\&data=2014-05-15\&origem=TRT>. Acesso em: 8 abr. 2015.

- Tribunal Regional do Trabalho da $5^{\mathrm{a}}$ Região, Bahia. Acórdão. Recurso Ordinário n 0000820-65.2014.5.05.0195. 3a Turma. Motivo ensejador da ruptura contratual - justa causa. Relator Des. Humberto Jorge Lima Machado. Diário de Justiça, Bahia, 13 mar. 2015b. Disponível em: <http://www.trt5.jus.br/consultaprocessos/modelo/ consulta_documento_blob.asp?v_id=AAAb0CADDAADKxUAAb>. Acesso em: 10 abr. 2015.

. Tribunal Regional do Trabalho da $8^{a}$ Região, Pará. Despacho. Reclamação Trabalhista $n^{\circ}$ 0002736-51.2013.5.08.0110. $1^{\text {a }}$ Vara do Trabalho de Tucuruí. Juiz Ney Maranhão. 22 jun. 2015b. Disponível em: <http://www2.trt8.jus.br/BDProducao/formulario/Imprimir_ Expediente.asp?sCdRelatorio=ExpedienteCertidao_Relatorio.asp\&iNrE xpediente $=3981 \& \mathrm{iNrExpedienteAno}=2015 \& \mathrm{iNrProcessoVara}=110 \& \mathrm{iNr}$ nstancia=1>. Acesso em: 22 jun. 2015.

CASTELLS, Manuel. A sociedade em rede. Trad. Roneide Venancio Majer. 8. ed. São Paulo: Paz e Terra, 1999. v. 1.

. A sociedade em rede: do conhecimento à política. In:

; CARDOSO, Gustavo (Org.). A sociedade em rede: do conhecimento à acção política. Belém: Imprensa Nacional - Casa da Moeda, 2005. p. 17-30.

DAQUINO, Fernando. A história das redes sociais: como tudo começou. 2012. Disponível em: <http://www.tecmundo.com.br/redessociais/33036-a-historia-das-redes-sociais-como-tudo-comecou.htm>. Acesso em: 4 abr. 2015. 
FERREIRA, Lívia Bergo Coelho. A revolução das tecnologias de informação e comunicação: consequências sociais, econômicas e culturais. Revista Digital de Biblioteconomia e Ciência da Informação, Campinas, v.7, n. 1, p. 117-127, jul./dez. 2009.

FERREIRA, Marcelo José Ferraz. Whatsapp e custos desnecessários. Revista Exame, São Paulo, 10 mar. 2015. Disponível em: <http:// exame.abril.com.br/rede-de-blogs/advogado-corporativo/2015/03/10/ whatsapp-e-custos-desnecessarios/>. Acesso em: 10 abr. 2015.

FERREIRA, Paulo Roberto Gaiger; RODRIGUES, Felipe Leonardo. Ata notarial: doutrina, prática e meio de prova. São Paulo: Quartier Latin, 2010.

FACEBOOK supera estimativa de receita de analistas; usuários já são 1,4 bi. Folha de São Paulo, São Paulo, 28 jan. 2015. Disponível em: <http://www1.folha.uol.com.br/tec/2015/01/1581963-facebooksupera-estimativa-de-receita-de-analistas-usuarios-ja-sao-14-bi.shtml>. Acesso em: 4 abr. 2015.

GORENDER, Jacob. Globalização, tecnologia e relações de trabalho. Estudos Avançados, São Paulo, v. 11, n. 29, p. 311-361, 1997.

IPIENS, José Antonio Escartin. El acta notarial de presencia en el proceso. Revista del Notariado, Buenos Aires, n. 399, 1952.

KALMAN, Yoram M.; RAFAELI, Sheizaf. Modulating synchronicity in computer mediated communication. In: CONFERENCE OF THE INTERNATIONAL COMMUNICATION ASSOCIATION, San Francisco, 2007. Proceedings.... Disponível em: <http://www.kalmans.com/ synchasynchlCAsubmit.pdf>. Acesso em: 3 abr. 2015.

MACHADO, Caren Silva; GOLDSCHMIDT, Rodrigo. Possibilidades do Facebook no Mundo do Trabalho. In: MISAILIDIS, Mirta Gladys Lerena Manzo de; SILVA, Lucas Gonçalves da; BARBATO, Maria Rosaria (Coord.). (Re) Pensando o direito: desafios para a construção de novos paradigmas. 23. ed. Florianópolis: Conpedi, 2014. p. 353-370. Disponível em: <http://www.publicadireito.com.br/ artigos/?cod=a5bb29b6db3cc79d>. Acesso em: 14 jun. 2016. 
MANFREDI, Silvia Maria; BASTOS, Solange. 1998, Propostas e experiências de formação profissional no âmbito das organizações de trabalhadores. Cedes Unicamp, maio 1998. Disponível em: <http:// www.cedes.unicamp.br/pesquisa/artigos/MANFREDI/indice.html>. Acesso em: 3 abr. 2015.

NASCIMENTO, Amauri Mascaro. Curso de direito do trabalho. 26. ed. São Paulo: Saraiva, 2011.

ROMANI, Bruno. Fórum trabalhista de SP usa WhatsApp para conciliação em processos. Folha de São Paulo, 10 jun. 2015. Disponível em: <http://www1.folha.uol.com.br/tec/2015/06/1640252forum-trabalhista-de-sp-usa-whatsapp-para-conciliacao-em-processos. shtml>. Acesso em: 30 jun. 2015.

SILVA, Otavio Pinto e. A nova face do direito do trabalho: tecnologia, desemprego, trabalho autônomo e trabalho informal. Revista do Advogado, São Paulo, v. 25, n. 82, p. 95-103, 2005.

TOMASZEWSKI, Adauto de Almeida. A ata notarial como meio de prova e efetivação de direitos. Rev. Ciên. Jur. e Soc. da Unipar, Umuarama, v. 11, n. 1, p. 7-23, jan./jun. 2008.

ENFERMEIRA que filmou Neymar em hospital de Fortaleza é demitida. UOL, São Paulo, 6 jul. 2014. Disponível em: <http://copadomundo.uol. com.br/noticias/redacao/2014/07/06/enfermeira-e-demitida-por-filmare-ironizar-neymar-em-hospital-de-fortaleza.htm>. Acesso em: 3 abr. 2015.

WHATSAPP. WhatsApp Inc, 2015. Disponível em: <https://www. whatsapp.com/>. Acesso em: 4 abr. 2015.

YANEZ, Oscar Vallejo. El instrumento público y las actas de notoriedad. Revista Notarial, Buenos Aires, v. 808, 1973.

Recebido em: 13/07/2015

Aprovado em: 29/02/2016 